\title{
XAFS study of starch-stabilized magnetite nanoparticles and surface speciation of arsenate
}

\author{
Meiyi Zhang ${ }^{\mathrm{a}}$, Gang Pan ${ }^{\mathrm{a}, *}$, Dongye Zhao ${ }^{\mathrm{b}}$, Guangzhi He ${ }^{\mathrm{a}}$

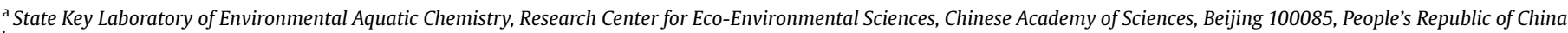 \\ ${ }^{\mathrm{b}}$ Environmental Engineering Program, Department of Civil Engineering, 238 Harbert Engineering Center, Auburn University, Auburn, AL 36849, USA
}

\section{A R T I C L E I N F O}

Article history:

Received 15 April 2011

Received in revised form

19 July 2011

Accepted 8 August 2011

\section{Keywords:}

Magnetite nanoparticle

Starch

Stabilization

XAFS

Arsenic removal

\begin{abstract}
A B S T R A C T
It has been shown that starch can effectively stabilize nanoscale magnetite particles, and starch-stabilized magnetite nanoparticles (SMNP) are promising for in situ remediation of arsenic-contaminated soils. However, a molecular level understanding has been lacking. Here, we carried out XAFS studies to bridge this knowledge gap. Fe K-edge XAFS spectra indicated that the Fe-O and Fe-Fe coordination numbers of SMNP were lower than those for bare magnetite particles, and these coordination numbers decreased with increasing starch concentration. The decrease in the average coordination number at elevated stabilizer concentration was attributed to the increase in the surface-to-volume ratio. Arsenic K-edge XAFS spectra indicated that adsorbed arsenate on SMNP consisted primarily of binuclear bidentate (BB) complexes and monodentate mononuclear (MM) complexes. More BB complexes (energetically more favorable) were observed at higher starch concentrations, indicating that SMNP not only offered greater adsorption surface area, but also stronger adsorption affinity toward arsenate.
\end{abstract}

(c) 2011 Elsevier Ltd. All rights reserved.

\section{Introduction}

Magnetite $\left(\mathrm{Fe}_{3} \mathrm{O}_{4}\right)$ nanoparticles have shown great potential for sorption of arsenic in contaminated soil and water because of the small particle size, large specific surface area, and high sorption capacity and affinity (Yean et al., 2005; Yavuz et al., 2006; Shipley et al., 2009; An et al., 2011). To prevent nanoparticles from aggregating, and thus, to enhance sorption capacity and soil deliverability, various particle stabilization strategies have been reported (Ponder et al., 2001; Raveendran et al., 2003; He and Zhao, 2005, 2007; He et al., 2007; Pan et al., 2010). Among various stabilizers tested, starch has been recognized as an effective, low-cost and environmentally benign material. Starch-stabilized magnetite nanoparticles (SMNP) have displayed much improved physical stability, soil mobility, and sorption capacity for arsenic compared with non-stabilized bare magnetite particles (He and Zhao, 2005; Zhang et al., 2010; An et al., 2011).

Previous studies have reported that magnetite particle size (Yean et al., 2005) and starch coating (He and Zhao, 2005) could strongly influence the arsenic adsorption capacity. However, a molecular level understanding has been lacking pertaining to the

\footnotetext{
* Corresponding author.

E-mail addresses: myzhang@rcees.ac.cn (M. Zhang), gpan@rcees.ac.cn (G. Pan) dzhao@eng.auburn.edu (D. Zhao), gzhhe@rcees.ac.cn (G. He).
}

mechanisms of particle stabilization, effect of starch on the structure of SMNP, and the mode of arsenic complexation on the nanoparticles. Such information is critical for predicting arsenic fate and transport in the environment as well as for guiding the design of more effective nanoscale sorbents for arsenic removal.

The material surface chemistry (surface functional groups, inorganic or organic coatings, etc.) and the electronic configuration of the surface complexes have major influences on the reactivity and properties ( $\mathrm{Nel}$ et al., 2006). In addition to size manipulation, particle stabilization can give rise to new types of 'surface sites' and/or sorption sites of altered proportions of edge/corner/step locations, leading to altered surface complexation reactivity and varied crystal chemistry (Zhang et al., 2003; Gilbert et al., 2004; Waychunas et al., 2005). The shifting of molecular orbital/band gap energy levels due to quantum confinement effects (Brus, 1983) can also change the redox characteristics of surface metals of the nanoparticles (Boily et al., 2001).

Synchrotron-based X-ray absorption spectroscopy is a widelyused technique for determining the local geometric and/or electronic structure of surface species (Waychunas et al., 1983; Peterson et al., 1997; Wilke et al., 2001; Morin et al., 2008; Missana et al., 2009; Wang et al., 2010). X-ray absorption near edge structure (XANES) is a powerful means to determine the overall oxidation state of iron, especially the pre-edge feature which is sensitive to Fe oxidation states (Waychunas et al., 1983). Extended X-ray absorption fine structure (EXAFS) is sensitive to crystal structure and the 
local environment of the absorbing atoms, and thus, can be employed to identify and quantify the local structure of arsenate binding with iron (Waychunas et al., 1986, 1993). Several recent EXAFS investigations have shown that at least two complexes exist in $\mathrm{As}(\mathrm{V})$-iron oxide adsorption system: binuclear bidentate complex and monodentate mononuclear complex (Fuller et al., 1993; Waychunas et al., 1993; Fendorf et al., 1997; Wang et al., 2010). However, detailed knowledge has been lacking on the nature of arsenic complexation at the surfaces of starch-stabilized magnetite nanoparticles.

The objectives of this study were to determine how starch as a nanoparticle stabilizer affects the structure of SMNP and the binding modes of arsenate on SMNP surfaces. XAFS spectroscopy was employed to examine the local structure of the arsenate complexes based on data from the As K-edge spectra, and to acquire insights into the local structure of the average Fe atoms by examining the Fe K-edge spectra.

\section{Materials and methods}

\subsection{Materials}

All chemicals were of the analytical grade. Ferrous chloride tetrahydrate $\left(\mathrm{FeCl}_{2} \cdot 4 \mathrm{H}_{2} \mathrm{O}\right)$ and ferric trichloride hexahydrate $\left(\mathrm{FeCl}_{3} \cdot 6 \mathrm{H}_{2} \mathrm{O}\right)$ were purchased from Tianjin Chemical Co., China. Arsenate stock solution was prepared from sodium arsenate $\left(\mathrm{Na}_{2} \mathrm{HAsO}_{4} \cdot 7 \mathrm{H}_{2} \mathrm{O}, \mathrm{ACS}, 98.0-102.0 \%\right.$, Alfa Aesar, China) and stored at $4{ }^{\circ} \mathrm{C}$. A water soluble starch was purchased from Shanghai Chemical Co., Shanghai, China. All solutions were prepared in ultrapure water (resistivity $18 \mathrm{M} \Omega$ ) obtained with a Liyuan UPW-10N ultrapure water system.

\subsection{Preparation of nanoparticles}

Starch-stabilized magnetite nanoparticles were synthesized by modifying the methods of Si et al. (Si et al., 2004) and He et al. (He and Zhao, 2005). In brief, a solution of $\mathrm{FeCl}_{3}(0.50 \mathrm{~mol} / \mathrm{L}, 100 \mathrm{ml})$ and $\mathrm{FeCl}_{2}(0.25 \mathrm{~mol} / \mathrm{L}, 100 \mathrm{ml})$ were added dropwise to a series of starch solutions under continuous shaking and $\mathrm{N}_{2}$ purging. Then, the $\mathrm{pH}$ of the solution was increased to 11 by adding $0.5 \mathrm{~mol} / \mathrm{L} \mathrm{NaOH}$ solution. Eqn. (1) describes the stoichiometry of the magnetite formation:

$\mathrm{Fe}^{2+}+2 \mathrm{Fe}^{3+}+8 \mathrm{OH}^{-} \rightarrow \mathrm{Fe}_{3} \mathrm{O}_{4}+4 \mathrm{H}_{2} \mathrm{O}$

The reaction mixtures were subsequently aged for $1 \mathrm{~h}$ with constant shaking and then allowed to grow in standstill and at room temperature $\left(22^{\circ} \mathrm{C}\right)$ for $24 \mathrm{~h}$. The final magnetite concentration was fixed at $0.04 \mathrm{~mol} / \mathrm{L}$ in all cases, while the starch concentration was varied at $0 \%, 0.025 \%, 0.05 \%, 0.1 \%$ and $0.5 \%(\mathrm{w} / \mathrm{v})$. The resultant magnetite particles were separated by a permanent magnet, washed 5 times with water, and then finally dried into powder at $60^{\circ} \mathrm{C}$ for $48 \mathrm{~h}$ in a vacuum oven.

\subsection{Characterizations of magnetite nanoparticles}

The mean diameter and particle size distribution of the magnetite nanoparticles with/without starch loading were determined by laser light scattering (LLS) with a Brookhaven BI-200SM goniometer (USA) at a scattering angle of $90^{\circ}$, a wavelength of $532 \mathrm{~nm}$ and a temperature of $25 \pm 0.1^{\circ} \mathrm{C}$.

\subsection{Preparation of arsenate-adsorbed magnetite samples}

Arsenate adsorption tests were carried out with the magnetite particles to acquire arsenate-adsorbed magnetite samples for XAFS analyses. Starch-stabilized particles prepared in the presence of various concentrations of starch were mixed with an arsenate solution in a series of polypropylene centrifuge tubes to yield a mixture volume of $30 \mathrm{ml}$, an SMNP concentration of $1 \mathrm{~g} \mathrm{Fe} / \mathrm{L}$ and an initial arsenate concentration of $40 \mathrm{mg} / \mathrm{L}$. The tubes were then capped and shaken for $24 \mathrm{~h}$, which was sufficient for the adsorption to reach equilibrium (proven through separate kinetic tests). All the adsorption experiments were conducted at $25{ }^{\circ} \mathrm{C}$ and $\mathrm{pH}$ 7.0. A constant ionic strength was maintained at $0.01 \mathrm{~mol} / \mathrm{L}$ by adding appropriate amounts of $\mathrm{NaNO}_{3}$. The $\mathrm{pH}$ of the reaction system was constantly monitored and adjusted intermittently to the desired value of 7.0 with $0.1 \mathrm{~mol} / \mathrm{L} \mathrm{NaOH}$ or $0.1 \mathrm{~mol} / \mathrm{L}$ $\mathrm{HNO}_{3}$. Upon equilibrium, the suspensions were centrifuged and the moist solids of the arsenic-laden magnetite particles were mounted in a 2-mm-thick cell and sealed with adhesive PVC tape for XAFS analyses.

\subsection{XAFS data collection and analysis}

XAFS spectra were obtained for various As-free and As-laden magnetite samples. The XAFS analyses were performed on the beam lines 1W1B of the Beijing
Synchrotron Radiation Facility (BSRF) and BL14W1 of the Shanghai Synchrotron Radiation Facility (SSRF), China. The arsenate-free SMNP powder samples of various starch concentrations were pasted on the adhesive PVC tapes, and the arsenateloaded SMNP samples were sealed between two layers of the adhesive PVC tape to prevent moisture loss. Energy ranges of -200 to $1000 \mathrm{eV}$ from the K-edge of Fe $(7112 \mathrm{eV})$ and As $(11,868 \mathrm{eV})$ were used to collect the spectra under ambient conditions. The Fe K-edge XAFS spectra of the arsenate-free SMNP samples were collected at room temperature in the transmission mode, whereas the spectra for arsenate-loaded samples were collected in the fluorescence mode using a Lytle detector. For comparison, XAFS spectra for a standard reference arsenate $\left(\mathrm{Na}_{2} \mathrm{HA}\right.$ $\mathrm{sO}_{4} \cdot 7 \mathrm{H}_{2} \mathrm{O}$ ) were acquired in the transmission mode. An average of three scans was carried out to achieve an adequate signal/noise ratio.

The resultant EXAFS data were analyzed with the Winxas 3.1 software (Ressler, 1998). The spectra were processed by removing the background absorbance normalizing the atomic absorption, and extracting the EXAFS signals from the spectra. The coordination numbers $(C N)$ and interatomic distances $(R)$ were then determined by fitting the model-simulated values to the experimental spectra ( $\mathrm{Li}$ et al., 2004, 2008; Pan et al., 2004).

\section{Results and discussion}

\subsection{Physical characteristics of magnetite nanoparticles with/without starch loading}

The particle sizes of magnetite nanoparticles at various starch levels are shown in Fig. 1. Fig. 1 indicated that starch can strongly affect the particle settleability. The particle size of magnetite nanoparticles decreased from $124.7 \mathrm{~nm}$ to $11.5 \mathrm{~nm}$ with the starch loading increased from 0 to 0.5 wt.\%.

Without starch as a stabilizer, the nanoparticles were bridged and large flocs were formed that precipitated easily. At elevated starch concentrations, the surface of each particle was gradually covered with stabilizer molecules, which induce a strong steric repulsion force preventing the particles from aggregating, leading to complete stabilization of the particles.

\subsection{XAFS analysis of arsenic-free SMNP}

Fig. 2 shows the normalized XAFS and XANES (inset) spectra for bare and starch-stabilized $\mathrm{Fe}_{3} \mathrm{O}_{4}$ particles. The peak at $7.112 \mathrm{keV}$ is attributed to quadrupole transitions from the $1 \mathrm{~s}$ to $3 \mathrm{~d}$ orbitals (Wilke et al., 2001; Chen et al., 2002). The peak at $7.132 \mathrm{keV}$ shows the d-p hybriding between the metal atoms and ligands through bonding and multiple scatterings involving the same atoms with different scattering paths (Ankudinov et al., 2000). The Fe K-edge XANES spectra do not show any energy shift, indicating that iron of

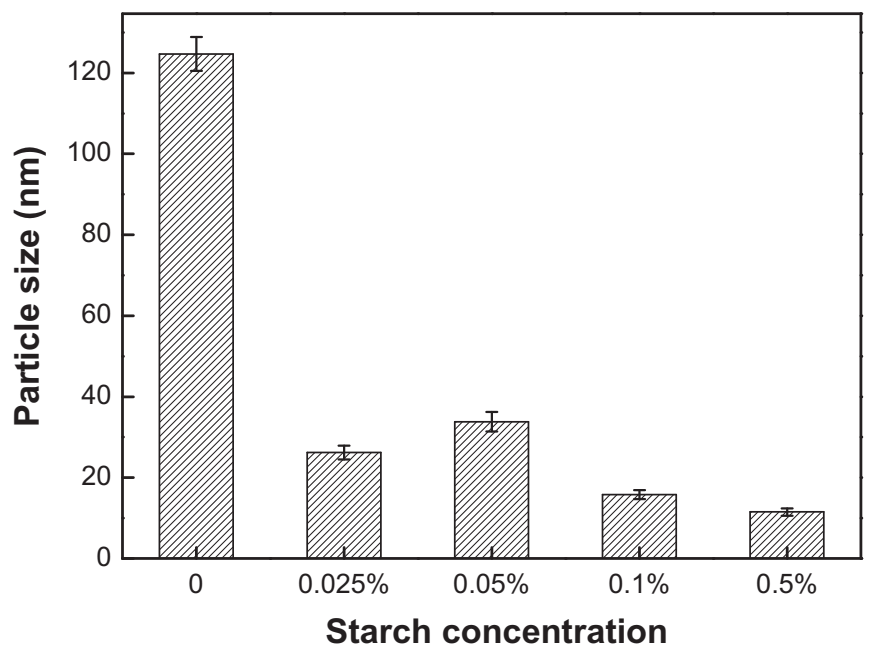

Fig. 1. Particle sizes of magnetite nanoparticles at various starch levels determined by LLS. 


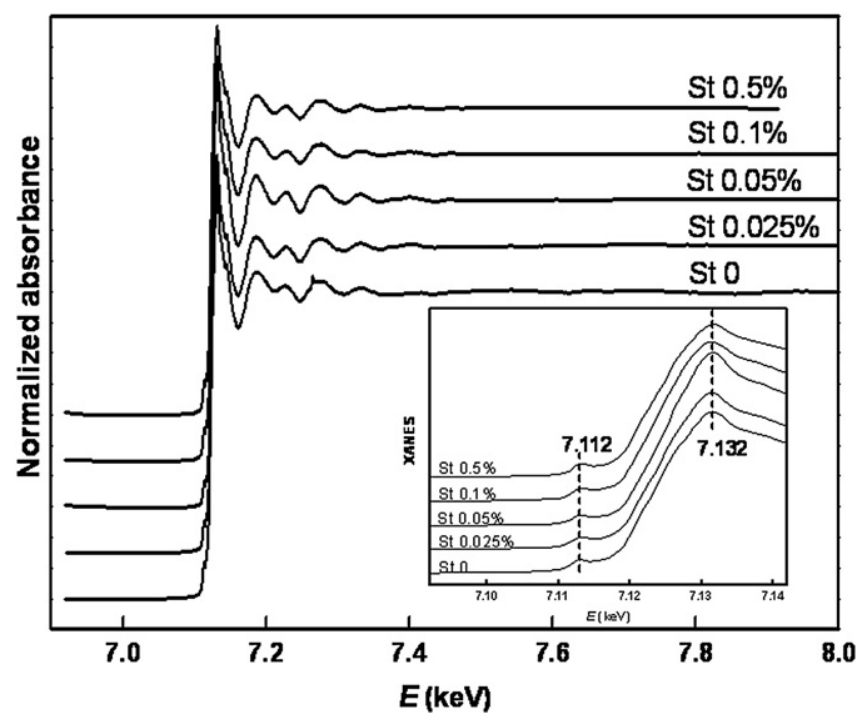

Fig. 2. Normalized Fe K-edge XAFS and XANES spectra (inset) for a series of SMNP prepared at a starch concentration of $0,0.025 \%, 0.05 \%, 0.1 \%$, and $0.5 \%$, respectively.

the SMNP samples is oxidized to the same extent in the presence of various levels of starch, i.e. the starch used in the process of SMNP synthesis does not change the valences of iron atoms.

Fig. 3 shows the Fourier transforms (FT) of the EXAFS spectra for SMNP prepared at various starch levels as well as for a commercial magnetite powder. The first peak in the Fourier transforms reveals information on the $\mathrm{Fe}-\mathrm{O}$ correlations. The peaks near 1.1 and $1.5 \AA$ arise dominantly from 4-coordinated and 6-coordinated $\mathrm{Fe}-\mathrm{O}$ subshells, respectively. The second peak in Fig. 3 yields information on the Fe-Fe correlations. The peaks near 2.6 and $3.0 \AA$ arise from 4-coordinated and 6-coordinated $\mathrm{Fe}-\mathrm{Fe}$ subshells, respectively (Pinakidou et al., 2008).

The FT amplitude of the peaks in Fig. 3 decreases with decreasing starch concentration except for the St 0.05\% sample, suggesting that there exists a correlation between the particle size and the FT peak magnitude. This phenomenon can be attributed to

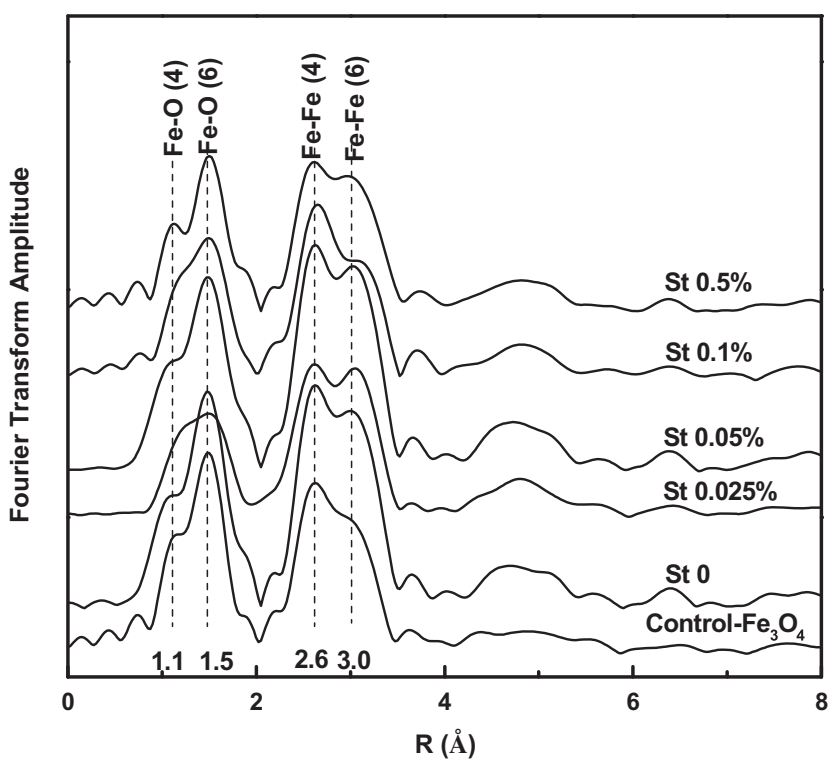

Fig. 3. Fourier transforms of EXAFS spectra for SMNP prepared at various starch levels as well as for a commercial $\mathrm{Fe}_{3} \mathrm{O}_{4}$ powder. the substantial structural disorder at the surface of the nanoparticles (Choi et al., 2002; Masataka et al., 2006). The degree of disorder and distortion is expected to increase with decreasing particle size (Shido and Prins, 1998). The magnitude of the FT peak is inversely related to the Debye-Waller factor corresponding to the mean square relative displacement of the interatomic distance due to static disorder and thermal vibrational disorder (Choi et al., 2002). In the present system, the systematic decrease in the FT magnitude is primarily due to an increase in static disorder rather than a thermal vibrational effect. These results indicate that the starch coating on the magnetite particles can induce substantial structural disorder corresponding to the relative amounts of hexahedron and octahedron in the magnetite system.

A similar trend can be found in the coordination numbers of iron clusters in SMNP (Table 1). While the $\mathrm{Fe}-\mathrm{O}$ distance is about constant $(1.95 \pm 0.01 \AA)$ for all the samples, the coordinate numbers range from 4.1 to 5.6. Two Fe-Fe subshells fit well to the experimental results (residuals $<15$ in Table 1), indicating a $\mathrm{Fe}-\mathrm{Fe}$ coordination number of about 1.1-5.6 at a bond distance of $3.01 \pm 0.04 \AA$ and about $2.5-8.3$ at $3.46 \pm 0.04 \AA$ (Table 1). The $\mathrm{Fe}-\mathrm{Fe}$ bond distances are similar to those reported in previous findings (Corrias et al., 2000). With increasing starch concentration from 0 to $0.5 \%$, the value of $C N_{\mathrm{Fe}-\mathrm{O}}$ decreases from 5.5 to 4.1 and $\mathrm{CN}_{\mathrm{Fe}-\mathrm{Fe}}$ from 10.3 to 6.5 . The case for the SMNP-St $0.05 \%$ sample appears to be an outlier and will be addressed later on. Given that the particles are prepared following otherwise identical procedures, the addition of starch during the particle synthesis should be held responsible for the observed differences in the molecular structures.

The $C N$ value of 4 would be expected for the $\mathrm{Fe}-\mathrm{O}$ bond in the bulk phase, and the values for $C N_{1}$ and $C N_{2}$ are expected to be 4 and 8 , respectively, since $\mathrm{Fe}_{3} \mathrm{O}_{4}$ has an inverse spinel structure (Krylov et al., 2000). However, the observed coordination number values of the stabilized nanoparticles are lower than those of the bulk particles owing to the higher surface-to-volume ratios for smaller particles (Guo et al., 2000).

Being a neutral macromolecule, starch stabilizes particles through the steric stabilization mechanism. Our previous FTIR spectra of $\mathrm{Fe}_{3} \mathrm{O}_{4}$ prepared at various starch concentrations revealed that compared with neat soluble starch, the IR characteristic peaks shifted to a lower wavenumber for starch-coated magnetite, indicating that there was a chemical bonding between the soluble starch and $\mathrm{Fe}_{3} \mathrm{O}_{4}$ (Ding et al., in press). Based on the microstructure and characteristics of chemical bonds of starch molecules, such as indican bonds and intermolecular hydrogen bonds, revealed by quantum chemistry calculation (Long et al., 2002), the binding of starch onto the surface of $\mathrm{Fe}_{3} \mathrm{O}_{4}$ particles can be deduced (Scheme 1). Scheme 1 shows that starch is bonded to magnetite through reactions with the surface hydroxyl groups of the $\mathrm{Fe}_{3} \mathrm{O}_{4}$ particles.

Table 1

Fitted Fe K-edge EXAFS parameters for SMNP samples prepared at various starch concentrations.

\begin{tabular}{|c|c|c|c|c|c|c|c|c|}
\hline \multirow[t]{2}{*}{ Sample } & \multicolumn{2}{|c|}{$\mathrm{Fe}-\mathrm{O}$} & \multicolumn{4}{|c|}{$\mathrm{Fe}-\mathrm{Fe}$} & \multirow[t]{2}{*}{ Res. } & \multirow[t]{2}{*}{$C N_{1}+C N_{2}$} \\
\hline & $C N$ & $R$ & $\mathrm{CN}_{1}$ & $R$ & $\mathrm{CN}_{2}$ & $R$ & & \\
\hline SMNP-St 0 & 5.5 & 1.94 & 2.0 & 2.98 & 8.3 & 3.44 & 7.81 & 10.3 \\
\hline SMNP-St $0.025 \%$ & 4.4 & 1.94 & 1.1 & 3.00 & 7.0 & 3.43 & 6.58 & 8.1 \\
\hline SMNP-St 0.05\% & 5.6 & 1.95 & 5.6 & 3.03 & 3.2 & 3.46 & 13.0 & 8.8 \\
\hline SMNP-St $0.1 \%$ & 4.3 & 1.96 & 4.0 & 3.05 & 2.5 & 3.50 & 6.64 & 6.5 \\
\hline SMNP-St $0.5 \%$ & 4.1 & 1.96 & 3.1 & 3.01 & 3.5 & 3.46 & 10.3 & 6.6 \\
\hline
\end{tabular}

Note: $C N$, coordinate number, is the number of atoms in a shell at distance $R(\AA)$ from the central atom. Measurement errors are about $5-15 \%$ for the coordinate numbers. The residual (Res.) gives a measure of the agreement between experimental and theoretical EXAFS curves. Res. $<15$ in all cases, indicating very good fitting quality. 


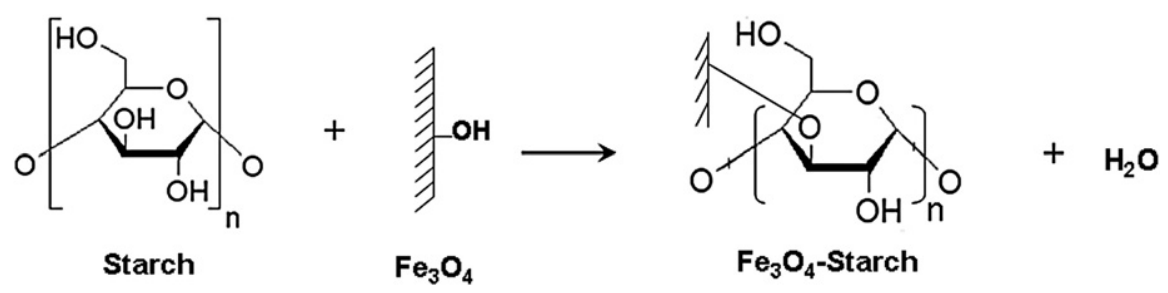

Scheme 1. Schematic diagram of starch-binding onto magnetite.

It has been reported that the addition of $\mathrm{NaOH}$ to a dispersion of starch granules induces rapid swelling of the starch granules, and both the $\mathrm{NaOH} /$ water ratio and $\mathrm{NaOH} /$ starch ratio can affect the dispersion and gelatinization of the starch solution (Roberts and Cameron, 2002). The presence of $\mathrm{NaOH}$ accelerates the hydrolysis of the starch chains and breaks down the continuous starch network. In addition, when $\mathrm{NaOH}$ penetrates into the interior of the starch granules, it can react with the hydroxyl groups on starch to form some kinds of starch sodium salt (Scheme 2). This salification may reduce the hydrogen bonding between the starch molecules, and even decrease the starch coating on the particle surface at elevated $\mathrm{pH}$. On the other hand, however, the negatively charged functional groups of the modified starch may further enhance the stabilization effects due to additional electrostatic stabilization effect.

It was noteworthy that the FT peak height and coordination number for the SMNP-St 0.05\% appeared extraneous to the starch concentration, which will be discussed in the Section 3.3.

\subsection{XAFS analysis of arsenate-loaded SMNP}

Fig. 4 shows the Fourier transforms of the EXAFS spectra from arsenate-loaded SMNP samples. The first peak at around $1.67 \AA$ in the Fourier transforms yields information on the As-O correlations. The second substantial peak at 2.3-3.8 $\AA$ in the Fourier transforms indicates the existence of an ordered cation shell beyond the oxygen shell (i.e. the formation of inner-sphere complexes), which is due mainly to the As-Fe correlations. Long As-O correlations must also exist, but mainly in the vicinity of the absorption edge or at the beginning of the EXAFS spectra (Waychunas et al., 1993). The different shapes of the spectra in Fig. 4 suggest that different adsorption complexes co-exist, and relative populations between different adsorption complexes vary with the starch concentration.

Table 2 gives the micro-structural details of arsenate adsorbed on the SMNP surfaces. The dominant peak is attributed to a shell of 3.8-4.2 oxygen atoms at an As-O interatomic distance of $1.68 \pm 0.01 \AA$. This distance corresponds closely to previously reported EXAFS studies of arsenic adsorbed and is characteristic of the $\mathrm{As}(\mathrm{V})$ species (Waychunas et al., 1993; Morin et al., 2008). The second peak at around 2.3-3.5 ^ (Fig. 4) can be ascribed to two As-Fe shells (Table 2): $1.9-2.4 \mathrm{Fe}$ atoms at $3.30 \pm 0.04 \AA$ and
$0.8-1.4$ Fe atoms at $3.70 \pm 0.05 \AA$, which were attributed to bidentated binuclear mode (BB) and monodentated mononuclear (MM) binding modes, respectively. Addition of a second As-Fe subshell to the back-transform fits did not notably affect the first subshell fitted parameters; rather, it improved the fitting quality in the arsenate-loaded samples spectra.

Based on our previous research (He et al., 2009a,b; Zhang et al., 2009), adsorption of arsenate on SMNP surfaces may proceed through a two-step reaction process. The initially formed MM adsorption complexes could either keep stable temporarily or transfer to the thermodynamically more stable BB adsorption complexes in the second step depending on the surface coverage. When the surface coverage is low or when enough active sites are available, an MM linkage can be relaxed to the BB bonding mode. For the 4 samples in Table 2, the $C N_{1}+C N_{2}$ values in the starchcoated magnetite samples are higher than those of the bare magnetite particles, indicating that the starch coating facilitated the formation of more stable adsorbing sites on the magnetite particle surfaces. To our knowledge, this is the first direct evidence that starch-stabilized nanoparticles offer stronger adsorption affinity toward arsenate than bare magnetite particles. As starch stabilization has been known to increase the specific surface area of the resultant nanoparticles (He and Zhao, 2005), and as more sorption sites favor the transformation from the MM binding mode to BB binding mode, starch-coated magnetite particles offer both greater sorption capacity and stronger affinity than bare magnetite particles.

As mentioned earlier, the samples of SMNP-St 0.05\% and SMNPAs-St $0.05 \%$ behave extraneously in terms of concentration dependence compared to the other samples. As shown in Table 1 and Fig. 3, with increasing starch concentrations from 0 to $0.5 \%$, the magnitude of peaks and coordination numbers of $\mathrm{Fe}-\mathrm{O}$ bond and $\mathrm{Fe}-\mathrm{Fe}$ bond decrease, except for the case of SMNP-St $0.05 \%$. Similar phenomenon was also observed in the arsenic adsorbed samples. Table 2 shows that the $C N_{1}+C N_{2}$ value in the starchcoated magnetite samples shows a generally increasing trend with increasing starch concentration, except for the SMNP-As-St $0.05 \%$ sample, which has the highest $C N_{1}+C N_{2}$ value. It can be therefore deduced that the starch concentration at $0.05 \%$ has the lowest influence on the structure of SMNP, and arsenate adsorbed on SMNP-St $0.05 \%$ can result in more BB surface complexes. This

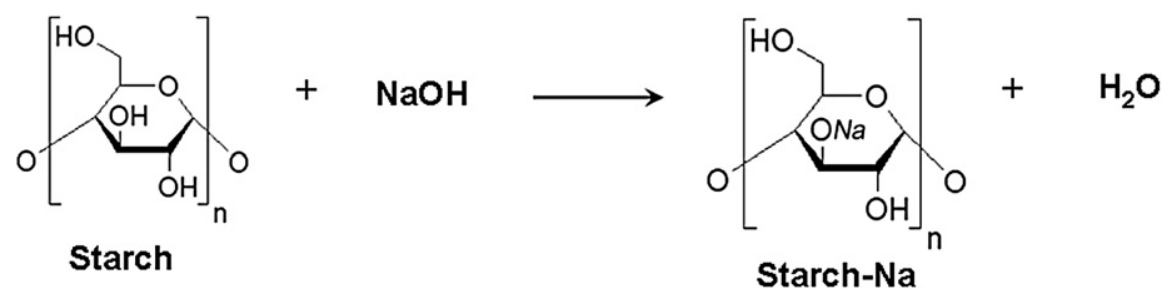

Scheme 2. Schematic diagram of the salinization of starch by $\mathrm{NaOH}$. 


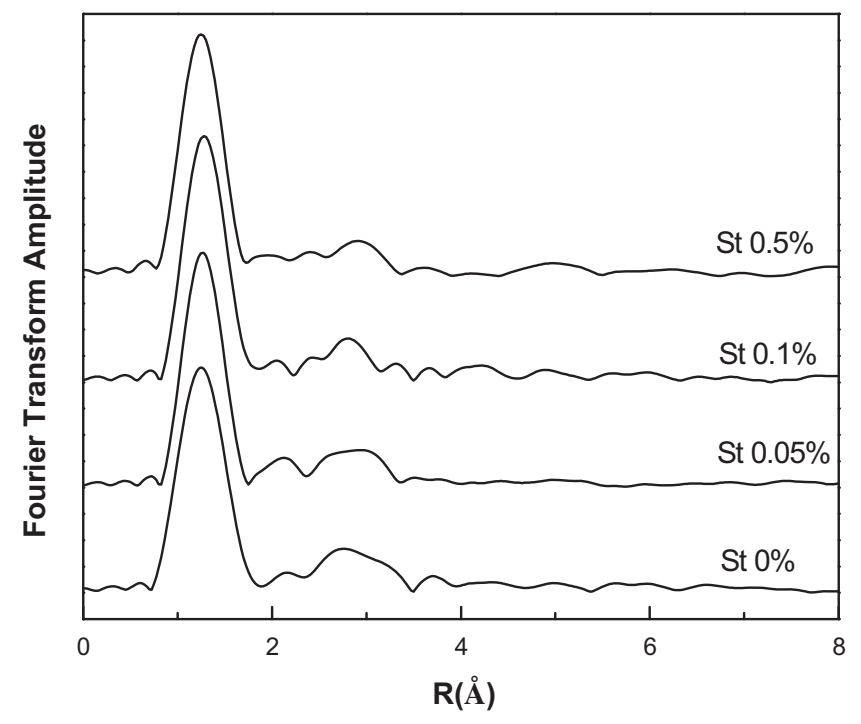

Fig. 4. Fourier transforms of the EXAFS of arsenate-adsorbed SMNP surfaces. The initial concentration of arsenate is $40 \mathrm{mg} / \mathrm{L}$, and the particle concentration of SMNP is $1.0 \mathrm{~g} \mathrm{Fe} / \mathrm{L}$.

phenomenon may be attributed to a number of factors associated with starch and $\mathrm{NaOH}$. As mentioned earlier, $\mathrm{NaOH}$ can partially functionalize starch; as a result, the steric stabilization is further enhanced through electrostatic stabilization facilitated by the resultant negative charges on starch. On the other hand, the charged starch molecules may compete more strongly with arsenate for the adsorption sites. Moreover, as the relative $\mathrm{NaOH} / \mathrm{starch}$ ratio can affect starch hydrolysis, more starch would be hydrolyzed for the particles prepared at $0.05 \%$ starch compared to the counterparts prepared at higher starch concentrations, resulting in reduced surface coating and stabilizing effects, yet freeing up more adsorption sites. The combination of these opposing effects leads to the unusual adsorption behavior of SMNP-St $0.05 \%$.

\subsection{Implications to arsenic remediation}

The adsorption characteristics of SMNP and their particle sizes could be manipulated by adjusting the concentration of starch. Starch can not only control the particle size of SMNP, but the adsorption affinity for arsenate. In the presence of elevated starch concentration, the energetically more stable BB complexes are formed predominantly on the SMNP surface. Consequently, starchstabilized magnetite nanoparticles may facilitate long-term immobilization of arsenic in soil and groundwater.

For in situ soil remediation, the starch-to-magnetite concentration ratio may be optimized during the preparation of SMNP by

Table 2

Best-fitted EXAFS parameters for adsorbed arsenate on SMNP surfaces.

\begin{tabular}{|c|c|c|c|c|c|c|c|c|}
\hline \multirow[t]{3}{*}{ Sample } & \multirow{2}{*}{\multicolumn{2}{|c|}{ As-O }} & \multicolumn{4}{|c|}{ As-Fe } & \multirow[t]{3}{*}{ Res. } & \multirow[t]{3}{*}{$C N_{1}+C N_{2}$} \\
\hline & & & \multicolumn{2}{|c|}{$\begin{array}{l}\text { BB linkage } \\
\text { mode }\end{array}$} & \multicolumn{2}{|c|}{$\begin{array}{l}\text { MM linkage } \\
\text { mode }\end{array}$} & & \\
\hline & $C N$ & $R$ & $C N_{1}$ & $R$ & $\mathrm{CN}_{2}$ & $R$ & & \\
\hline SMNP-As-St 0\% & 4.1 & 1.67 & 2.0 & 3.30 & 0.8 & 3.70 & 13.1 & 2.8 \\
\hline SMNP-As-St 0.05\% & 4.0 & 1.68 & 2.3 & 3.27 & 1.4 & 3.65 & 11.8 & 3.7 \\
\hline SMNP-As-St 0.1\% & 4.2 & 1.69 & 2.1 & 3.33 & 0.9 & 3.75 & 9.98 & 3.0 \\
\hline SMNP-As-St 0.5\% & 4.4 & 1.67 & 2.4 & 3.23 & 1.1 & 3.65 & 8.73 & 3.5 \\
\hline
\end{tabular}

Note: $C N$, coordinate number; $R$, distance from the central atom; Res., residual. taking into account the proper mobility of the nanoparticles in soil and maximizing arsenate adsorption affinity.

\section{Conclusions}

The application of starch as a stabilizer in preparation of the $\mathrm{Fe}_{3} \mathrm{O}_{4}$ particles is able to effectively reduce particle aggregation, and thus, particle size, resulting in much greater specific surface area and adsorption sites.

Moreover, the presence of starch leads to the formation of more effective adsorbing sites on magnetite particle surfaces. Arsenate is adsorbed on starch-stabilized magnetite nanoparticles mainly as inner-sphere bidentate and monodentate complexes. The coordination numbers of As-Fe binding increases with increasing starch concentration, which indicates that the arsenate is more firmly adsorbed at higher starch concentrations. The information gained from this work will be helpful in the development of stabilized nano-adsorbents for removal or immobilization of metal contaminants.

\section{Acknowledgments}

The study was funded by the NNSF of China (21007083, 20777090) and the National Basic Research Program of China (2010CB933600). We thank Beijing Synchrotron Radiation Facility (BSRF, China) and Shanghai Synchrotron Radiation Facility (SSRF, China) for providing the beam times.

\section{References}

An, B., Liang, Q., Zhao, D., 2011. Removal of arsenic(V) from spent ion exchange brine using a new class of starch-bridged magnetite nanoparticles. Water Research 45, 1961-1972.

Ankudinov, A.L., Rehr, J.J., Bare, S.R., 2000. Hybridization peaks in Pt-Cl XANES. Chemical Physics Letters 316, 495-500.

Boily, J.F., Lutzenkirchen, J., Balmes, O., Beattie, J., Sjoberg, S., 2001. Modeling proton binding at the goethite (alpha-FeOOH)-water interface. Colloids and Surfaces, A: Physicochemical and Engineering Aspects 179, 11-27.

Brus, L.E., 1983. A simple-model for the ionization-potential, electron-affinity, and aqueous redox potentials of small semiconductor crystallites. Journal of Chemical Physics 79, 5566-5571.

Chen, L.X., Liu, T., Thurnauer, M.C., Csencsits, R., Rajh, T., 2002. $\mathrm{Fe}_{2} \mathrm{O}_{3}$ nanoparticle structures investigated by X-ray absorption near-edge structure, surface modifications, and model calculations. Journal of Physical Chemistry B 106, 8539-8546.

Choi, H.C., Lee, S.Y., Kim, S.B., Kim, M.G., Lee, M.K., Shin, H.J., Lee, J.S., 2002. Local structural characterization for electrochemical insertion-extraction of lithium into $\mathrm{CoO}$ with X-ray absorption spectroscopy. Journal of Physical Chemistry B 106, 9252-9260.

Corrias, A., Ennas, G., Mountjoy, G., Paschina, G., 2000. An X-ray absorption spectroscopy study of the $\mathrm{Fe} \mathrm{K}$ edge in nanosized maghemite and in $\mathrm{Fe}_{2} \mathrm{O}_{3}-\mathrm{SiO}_{2}$ nanocomposites. Physical Chemistry Chemical Physics 2, 1045-1050.

Ding, C., Pan, G., Zhang, M. Preparation of starch-coated $\mathrm{Fe}_{3} \mathrm{O}_{4}$ and its phosphate removal properties. Chinese Journal of Environmental Engineering, in press.

Fendorf, S., Eick, M.J., Grossl, P., Sparks, D.L., 1997. Arsenate and chromate retention mechanisms on goethite. 1. Surface structure. Environmental Science and Technology 31, 315-320.

Fuller, C.C., Davis, J.A., Waychunas, G.A., 1993. Surface-chemistry of ferrihydrite. 2. Kinetics of arsenate adsorption and coprecipitation. Geochimica et Cosmochimica Acta 57, 2271-2282.

Gilbert, B., Huang, F., Zhang, H.Z., Waychunas, G.A., Banfield, J.F., 2004. Nanoparticles: strained and stiff. Science 305, 651-654.

Guo, L., Yang, S., Yang, C., Yu, P., Wang, J., Ge, W., Wong, G.K.L., 2000. Synthesis and characterization of poly(vinylpyrrolidone)-modified zinc oxide nanoparticles. Chemistry of Materials 12, 2268-2274.

He, F., Zhao, D., 2007. Manipulating the size and dispersibility of zerovalent iron nanoparticles by use of carboxymethyl cellulose stabilizers. Environmental Science and Technology 41, 6216-6221.

He, F., Zhao, D., Liu, J., Roberts, C.B., 2007. Stabilization of Fe-Pd nanoparticles with sodium carboxymethyl cellulose for enhanced transport and dechlorination of trichloroethylene in soil and groundwater. Industrial \& Engineering Chemistry Research 46, 29-34.

He, F., Zhao, D.Y., 2005. Preparation and characterization of a new class of starchstabilized bimetallic nanoparticles for degradation of chlorinated hydrocarbons in water. Environmental Science and Technology 39, 3314-3320. 
He, G., Pan, G., Zhang, M., Wu, Z., 2009a. Quantitative XANES studies on metastable equilibrium adsorption of arsenate on $\mathrm{TiO}_{2}$ surfaces. Journal of Physical Chemistry C 113, 17076-17081.

He, G., Zhang, M., Pan, G., 2009b. Influence of pH on initial concentration effect of arsenate adsorption on $\mathrm{TiO}_{2}$ surfaces: thermodynamic, DFT, and EXAFS interpretations. Journal of Physical Chemistry C 113, 21679-21686.

Krylov, A.S., Poliakoff, J.F., Stockenhuber, M., 2000. An Hermite expansion method for EXAFS data treatment and its application to FeK-edge spectra. Physical Chemistry Chemical Physics 2, 5743-5749.

Li, W., Pan, G., Zhang, M., Zhao, D., Yang, Y., Chen, H., He, G., 2008. EXAFS studies on adsorption irreversibility of $\mathrm{Zn}(\mathrm{II})$ on $\mathrm{TiO}_{2}$ : temperature dependence. Journal of Colloid and Interface Science 319, 385-391.

Li, X, Pan, G., Qin, Y, Hu, T., Wu, Z, Xie, Y, 2004. EXAFS studies on adsorptiondesorption reversibility at manganese oxide-water interfaces II. Reversible adsorption of zinc on delta- $\mathrm{MnO}_{2}$. Journal of Colloid and Interface Science 271, 35-40.

Long, J.Y., Long, X.Y., Ye, G.Z., 2002. A quantum chemistry research on electronic structure of starch molecules (I): characteristics of basic structure unit, indican bond and interior hydrogen bond. Guangxi Sciences 34-37, 42.

Masataka, K., Konishi, T., Kaneko, T., Sakamaki, M., Lin, L., Lin, J.G., Arvanitis, D., Fujikawa, T., 2006. Fe K-edge XAFS study of magnetite nanoparticles. Photon Factory Activity Report 24.

Missana, T, Alonso, U., Scheinost, A.C., Granizo, N., García-Gutiérrez, M., 2009. Selenite retention by nanocrystalline magnetite: role of adsorption, reduction and dissolution/co-precipitation processes. Geochimica et Cosmochimica Acta 73, 6205-6217.

Morin, G., Ona-Nguema, G., Wang, Y., Menguy, N., Juillot, F., Proux, O., Guyot, F., Calas, G., Brown Jr., G.E., 2008. Extended X-ray absorption fine structure analysis of arsenite and arsenate adsorption on maghemite. Environmental Science and Technology 42, 2361-2366.

Nel, A., Xia, T., Madler, L., Li, N., 2006. Toxic potential of materials at the nanolevel. Science 311, 622-627.

Pan, G., Li, L., Zhao, D., Chen, H., 2010. Immobilization of non-point phosphorus using stabilized magnetite nanoparticles with enhanced transportability and reactivity in soils. Environmental Pollution 158, 35-40.

Pan, G., Qin, Y., Li, X.L., Hu, T., Wu, Z., Xie, Y., 2004. EXAFS studies on adsorptiondesorption reversibility at manganese oxides-water interfaces I. Irreversible adsorption of zinc onto manganite (gamma-MnOOH). Journal of Colloid and Interface Science 271, 28-34.

Peterson, M.L., Brown, G.E., Parks, G.A., Stein, C.L., 1997. Differential redox and sorption of $\mathrm{Cr}(\mathrm{III} / \mathrm{VI})$ on natural silicate and oxide minerals: EXAFS and XANES results. Geochimica et Cosmochimica Acta 61, 3399-3412.

Pinakidou, F., Katsikini, M., Paloura, E.C., 2008. Determination of the crystallization ratio in a series of Fe-containing vitroceramic products by means of XAFS spectroscopies. Journal of Non-Crystalline Solids 354, 5053-5059.

Ponder, S.M., Darab, J.G., Bucher, J., Caulder, D., Craig, I., Davis, L., Edelstein, N., Lukens, W., Nitsche, H., Rao, L., Shuh, D.K., Mallouk, T.E., 2001. Surface chemistry and electrochemistry of supported zerovalent iron nanoparticles in the remediation of aqueous metal contaminants. Chemistry of Materials 13, 479-486.
Raveendran, P., Fu, J., Wallen, S.L., 2003. Completely green synthesis and stabilization of metal nanoparticles. Journal of the American Chemical Society 125 13940-13941.

Ressler, T., 1998. WinXAS: a program for X-ray absorption spectroscopy data analysis under MS-Windows. Journal of Synchrotron Radiation 5, 118-122.

Roberts, S.A., Cameron, R.E. 2002. The effects of concentration and sodium hydroxide on the rheological properties of potato starch gelatinisation. Carbohydrate Polymers 50, 133-143.

Shido, T., Prins, R., 1998. Why EXAFS underestimated the size of small supported MoS2 particles. Journal of Physical Chemistry B 102, 8426-8435.

Shipley, H.J., Yean, S., Kan, A.T., Tomson, M.B., 2009. Adsorption of arsenic to magnetite nanoparticles: effect of particle concentration, $\mathrm{pH}$, ionic strength, and temperature. Environmental Toxicology and Chemistry 28, 509-515.

Si, S., Kotal, A., Mandal, T.K., Giri, S., Nakamura, H., Kohara, T., 2004. Size-controlled synthesis of magnetite nanoparticles in the presence of polyelectrolytes. Chemistry of Materials 16, 3489-3496.

Wang, Y.H., Morin, G., Ona-Nguema, G., Juillot, F., Guyot, F., Calas, G., Brown, G.E., 2010 Evidence for different surface speciation of arsenite and arsenate on green rust: an EXAFS and XANES study. Environmental Science and Technology 44, 109-115.

Waychunas, G.A., Apted, M.J., Brown, G.E., 1983. X-ray K-edge absorption-spectra of Fe minerals and model compounds - neat-edge structure. Physics and Chemistry of Minerals 10, 1-9.

Waychunas, G.A. Brown, G.E., Apted, M.J. 1986. X-ray K-edge absorption-spectra of Fe minerals and model compounds .2. EXAFS. Physics and Chemistry of Minerals $13,31-47$

Waychunas, G.A., Kim, C.S., Banfield, J.F., 2005. Nanoparticulate iron oxide minerals in soils and sediments: unique properties and contaminant scavenging mechanisms. Journal of Nanoparticle Research 7, 409-433.

Waychunas, G.A., Rea, B.A., Fuller, C.C., Davis, J.A., 1993. Surface-chemistry of ferrihydrite. 1. EXAFS studies of the geometry of coprecipitated and adsorbed arsenate. Geochimica et Cosmochimica Acta 57, 2251-2269.

Wilke, M., Farges, F., Petit, P.-E., Brown Jr., G.E., Martin, F., 2001. Oxidation state and coordination of Fe in minerals: an Fe K-XANES spectroscopic study. American Mineralogist 86, 714-730.

Yavuz, C.T., Mayo, J.T., Yu, W.W., Prakash, A., Falkner, J.C., Yean, S., Cong, L., Shipley, H.J. Kan, A., Tomson, M., Natelson, D., Colvin, V.L., 2006. Low-field magnetic separation of monodisperse $\mathrm{Fe}_{3} \mathrm{O}_{4}$ nanocrystals. Science 314, 964-967.

Yean, S., Cong, L., Yavuz, C.T., Mayo, J.T., Yu, W.W., Kan, A.T., Colvin, V.L., Tomson, M.B. 2005. Effect of magnetite particle size on adsorption and desorption of arsenite and arsenate. Journal of Materials Research 20, 3255-3264.

Zhang, H., Huang, F., Gilbert, B., Banfield, J.F., 2003. Molecular dynamics simulations, thermodynamic analysis, and experimental study of phase stability of zinc sulfide nanoparticles. Journal of Physical Chemistry B 107, 13051-13060.

Zhang, M., He, G., Pan, G., 2009. Combined DFT and IR evidence on metastableequilibrium adsorption of arsenate on $\mathrm{TiO}_{2}$ surfaces. Journal of Colloid and Interface Science 338, 284-286.

Zhang, M., Wang, Y., Zhao, D., Pan, G., 2010. Immobilization of arsenic in soils by stabilized nanoscale zero-valent iron, iron sulfide ( $\mathrm{FeS})$, and magnetite $\left(\mathrm{Fe}_{3} \mathrm{O}_{4}\right)$ particles. Chinese Science Bulletin 55, 365-372. 